\title{
Simple Model for Simulating Characteristics of River Flow Velocity in Large Scale
}

\author{
Husin Alatas, 1,2 Dyo D. Prayuda, ${ }^{2}$ Achmad Syafiuddin, ${ }^{2}$ May Parlindungan, ${ }^{3}$ \\ Nurjaman O. Suhendra, ${ }^{3}$ and Hidayat Pawitan ${ }^{1,3}$ \\ ${ }^{1}$ Research Cluster for Dynamics and Modeling of Complex Systems, Faculty of Mathematics and Natural Sciences, \\ Bogor Agricultural University, Jl. Meranti, Kampus IPB Darmaga, Bogor 16680, Indonesia \\ ${ }^{2}$ Theoretical Physics Division, Department of Physics, Bogor Agricultural University, Jl. Meranti, Kampus IPB Darmaga, \\ Bogor 16680, Indonesia \\ ${ }^{3}$ Hydrometeorology Division, Department of Geophysics and Meteorology, Bogor Agricultural University, Jl. Meranti, \\ Kampus IPB Darmaga, Bogor 16680, Indonesia
}

Correspondence should be addressed to Husin Alatas; alatas@ipb.ac.id and Hidayat Pawitan; hpawitan@ipb.ac.id

Received 28 July 2014; Accepted 30 December 2014

Academic Editor: Alexey Stovas

Copyright (C) 2015 Husin Alatas et al. This is an open access article distributed under the Creative Commons Attribution License, which permits unrestricted use, distribution, and reproduction in any medium, provided the original work is properly cited.

We propose a simple computer based phenomenological model to simulate the characteristics of river flow velocity in large scale. We use shuttle radar tomography mission based digital elevation model in grid form to define the terrain of catchment area. The model relies on mass-momentum conservation law and modified equation of motion of falling body in inclined plane. We assume inelastic collision occurs at every junction of two river branches to describe the dynamics of merged flow velocity.

\section{Introduction}

The complexity of river network has been studied intensively over the past decades in order to describe its pattern formation and dynamics [1]. The evolution of river network pattern has been investigated based on various approaches such as continuum [2-4], stochastic [5], and cellular [6] approaches. On the other hand, one of the most important dynamical characteristics of a river is its flow velocity which corresponds to the water discharge along the river lines. Many different empirical models have been proposed to describe the associated dynamics in various scales and for various purposes as well [7-12]. Recently, Gauckler-Manning-Strickler (GMS) formula based empirical model has been implemented to describe the global river flow in certain area of Europe [9].

In the meantime, one of the theoretical descriptions of dynamics of open/close river channel is given by the so-called Saint Venant equations (SVEs) in one or two dimensions. These spatiotemporal equations are developed on the basis of mass-momentum conservation law in the form of coupled continuity and momentum differential equations of average water discharge and cross-sectional river flow channel functions where both need initial and boundary conditions [7, 1319]. Recently, one-dimensional SVE has been adopted in a coupled hydrodynamic analysis model to investigate the large scale water discharge dynamics at basin of Yangtze River, China, in the presence of complex river-lake interaction [7].

In general, the river flow dynamics is affected by friction, roughness, slope, and number of rocks. Usually, in SVEs all these parameters are incorporated in the GMS formula which is found empirically to approximate the average flow velocity in short distance [17]. However, solving SVEs to simulate the river flow dynamics in a large scale such as the whole area of catchment area is not an easy task. It can be done by solving either the two-dimensional SVE or the one-dimensional SVE incorporated by junction model with internal boundary conditions $[7,19,20]$. It is likely that, for large scale cases, the calculation to solve the related SVEs based on rigorous semianalytical or numerical methods can be very difficult and probably time consuming. One of the difficult challenges to solve these equations numerically for the corresponding cases is how to determine the corresponding initial conditions [7]. 


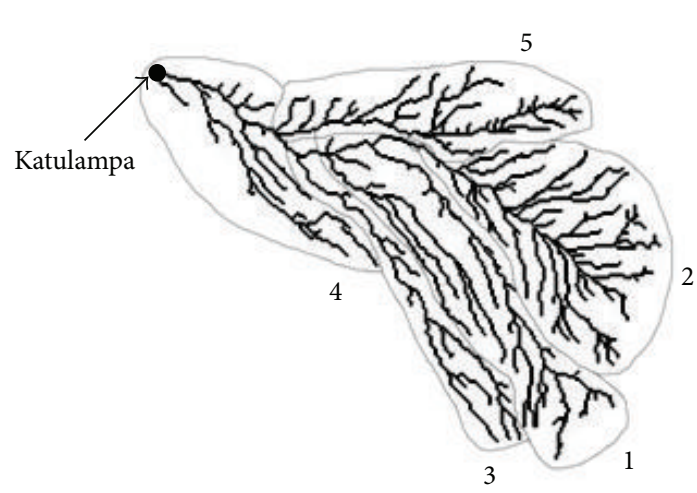

(a)

\begin{tabular}{|l|l|l|l|l|l|l|l|l|l|l|}
\hline 331 & 319 & 317 & 322 & 328 & 334 & 339 & 341 & 345 & 353 & 354 \\
\hline 313 & 314 & 323 & 321 & 325 & 331 & 337 & 341 & 345 & 351 & 357 \\
\hline 343 & 342 & 315 & 316 & 317 & 318 & 331 & 337 & 343 & 348 & 356 \\
\hline 345 & 345 & 316 & 336 & 333 & 326 & 322 & 335 & 340 & 343 & 348 \\
\hline 347 & 349 & 336 & 343 & 346 & 342 & 335 & 323 & 324 & 327 & 344 \\
\hline 348 & 350 & 340 & 347 & 350 & 353 & 353 & 350 & 345 & 340 & 329 \\
\hline 348 & 351 & 342 & 342 & 353 & 357 & 358 & 358 & 358 & 358 & 351 \\
\hline 350 & 351 & 354 & 355 & 343 & 356 & 361 & 362 & 363 & 366 & 366 \\
\hline 351 & 353 & 356 & 358 & 358 & 344 & 362 & 362 & 364 & 367 & 370 \\
\hline 350 & 353 & 357 & 360 & 362 & 347 & 363 & 365 & 365 & 367 & 372 \\
\hline 344 & 347 & 351 & 359 & 366 & 365 & 352 & 355 & 367 & 369 & 373 \\
\hline
\end{tabular}

(b)

FIGURE 1: (a) The network pattern of Ciliwung River catchment area which is divided into five regions. The solid dot represents the position of Katulampa observation point. (b) Modified DEM data of $90 \times 90 \mathrm{~m}^{2}$ grid resolution of a small area around Katulampa.

In this report, we propose a simple approach to develop a computer based discrete phenomenological model of river flow velocity. We still rely on mass-momentum conservation law by assuming that an inelastic collision occurs at a river junction. Instead of using GMS formula, to accommodate friction, roughness, and number of rocks in single parameter, here we introduce the notion of effective gravitational acceleration, whereas the flow velocity follows the equation of motion of falling body in inclined plane.

The procedure that we followed to develop the model includes the following: (i) determination of river catchment area in the form of a computational window grid, (ii) development of algorithm for flow velocity model, and (iii) examining the model characteristics with respect to the variations of initial water discharges at headwaters.

To our best knowledge, the proposed model has never been reported elsewhere. We compare our model with field observation data in order to justify the results. It should be emphasized from the beginning that this simple model is an attempt to determine characteristics of river flow velocity and it is not intended to replace SVEs. In principle, however, this model can also provide initial condition of the whole river network which is needed to solve numerically the corresponding time-dependent SVEs.

We considered the catchment area of Ciliwung River (CR) situated in West Java Province, Indonesia, for simulating the model. To define the corresponding terrain we used digital elevation model (DEM) in grid form which is constructed based on free shuttle radar topography mission (SRTM) data provided by USGS [20]. Each grid in DEM represents the average height within the corresponding terrain. We only take into account the surface runoff and exclude the subsurface runoff as well as landscape characteristics of surrounding river lines such as forest canopy, vegetation, land use, and sediment transport.

We organize this report as follows: in Section 2 we discuss the associated DEM of CR catchment area and then this is followed by the explanation of flow velocity model in Section 3. The results of our simulation and its discussion are given in Section 4. We conclude our report by a summary in
Section 5. Sections 2-4 discuss consecutively the abovementioned procedure that we followed.

\section{DEM of Ciliwung River Catchment Area}

The CR is one of the most important rivers in Java Island, Indonesia. It spans over $120 \mathrm{~km}$ from Mount Pangrango in West Java to Java Sea, north to the capital city Jakarta. Its catchment area is $149 \mathrm{~km}^{2}$. In recent years, during the rainy season, this river contributes around 30\% of flood in Jakarta.

To plot the CR catchment area we used DEM with $90 \times$ $90 \mathrm{~m}^{2}$ grid resolution and in order to get a more detailed terrain which still can be handled by modest computational facility, the associated DEM was corrected by $15 \times 15 \mathrm{~m}^{2}$ resolution DEM as well as data from field survey. Using GIS software this modified DEM was converted into numbers that can be read by Excel software. Shown in Figure 1(a) is the plot of $90 \times 90 \mathrm{~m}^{2}$ DEM of the corresponding CR river network pattern. It is obvious that water will flow to the lower land due to gravitational force, such that we can use this fact as a rule in our computer code to determine the corresponding river pattern based on the given DEM data after identifying the positions of all headwaters. Therefore, it is clear that the boundaries of all river branches which define a two-dimensional computational window are automatically provided by DEM, where each grid represents the corresponding computational mesh. In Figure 1(b) we give an example of specific small area of the corresponding computational window grid (see figure caption) which is highlighted with grey color grid. The number inside each grid represents DEM value in meter unit at specific position.

Based on our modified DEM, we identified that there are 126 headwaters. According to Strahler classification of river branches, all these headwaters converge into order 4 river channel at Katulampa area with channel dimension of $\sim 70 \mathrm{~m}$ width and $0.3-0.5 \mathrm{~m}$ water level. Similar to the most of tropical rivers, catchment upper area of CR is also filled up by rocks with relatively large size. 


\section{Flow Velocity Model}

We consider a discrete model where the water discharge is represented by the corresponding two-dimensional grid in the modified DEM in which its position is denoted by indices $(i, j)$. After determining the river network pattern, we model the corresponding flow velocity by assuming that its magnitude at particular position of water discharge along a river channel is given by the following equation:

$$
v(i, j)=\sqrt{v^{2}\left(i^{\prime}, j^{\prime}\right)+2 g_{\mathrm{eff}}\left(i^{\prime}, j^{\prime} ; h\right) \Delta H},
$$

where $v\left(i^{\prime}, j^{\prime}\right)$ and $v(i, j)$ denote the flow velocity of water discharge at higher and lower positions, respectively, while $\Delta H=H\left(i^{\prime}, j^{\prime}\right)-H(i, j)>0$ is the height $(H)$ difference, where the value of $H$ is provided by DEM. The symbol $g_{\text {eff }}$ represents the effective gravitational acceleration which is defined to accommodate the real condition of river channels and $h$ denotes water level from river bed at the position $\left(i^{\prime}, j^{\prime}\right)$. Flow velocities in (1) can be interpreted as the average of velocity in the associated grid. In the meantime, the width and water level of each river branch are assumed to be uniform.

In general, we assume that the parameter $g_{\text {eff }}$ depends on position and water level which can be determined empirically through field observation at particular time. The assumption of water level dependency is taken to accommodate the fact that water flow is more efficient as water level increases. But for the sake of simplicity, here we assume that $g_{\text {eff }}$ is uniform along all river channels and it will be determined later numerically. Comparing with the flow velocity expression in GMS formula, this parameter plays similar role with the ratio $R_{H}^{2 / 3} / n$ where $R_{H}$ is hydraulic radius of a river channel and $n$ represents roughness coefficient [9].

Next, to model the merging of flows from two different branches at a river junction we assume that the collision of water at each junction is inelastic satisfying the mass-momentum conservation law in the following discrete numerical scheme:

$$
\begin{aligned}
Q_{3}(i, j) & =Q_{1}(i, j)+Q_{2}(i, j), \\
\vec{p}_{3}(i, j) & =\vec{p}_{1}(i, j)+\vec{p}_{2}(i, j) .
\end{aligned}
$$

Here, $Q_{1}, Q_{2}, Q_{3}$ and $\vec{p}_{1}, \vec{p}_{2}, \vec{p}_{3}$ are the water discharge and momentum, respectively, as illustrated in Figure 2. Consider $\vec{p}=\rho Q \vec{v} \Delta t$ and $Q=h w v$, where $h$ and $w$ denote the water level from river bed and width of the river channel, respectively, while $\vec{v}$ and $v$ are, respectively, the flow velocity vector and its magnitude at the corresponding position. Here, we assume that the channel cross-section $(w \times h)$ is rectangular. Based on assumption that the collision is inelastic we can find from (1) and (2) the expression of flow velocity $v_{3}$ as follows:

$$
v_{3}=\frac{\sqrt{h_{1}^{2} w_{1}^{2} v_{1}^{4}+h_{2}^{2} w_{2}^{2} v_{2}^{4}+h_{1} h_{2} w_{1} w_{2} v_{1}^{2} v_{2}^{2} \cos \theta}}{h_{1} w_{1} v_{1}+h_{2} w_{2} v_{2}},
$$

where $\theta$ is the angle between $\vec{v}_{1}$ and $\vec{v}_{2}$. Note that after collision we only consider the related flow velocity magnitude,

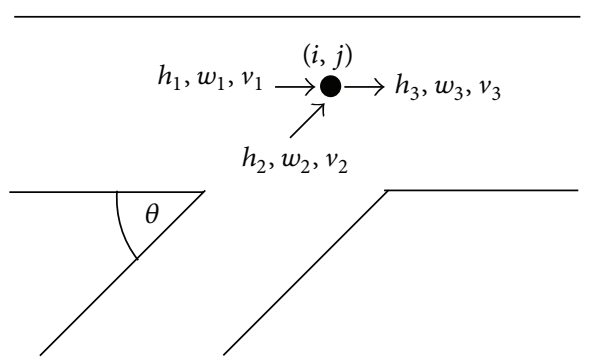

FIGURE 2: Illustration of the inelastic collision of two river branches.

while its direction follows the shape of the river channel. To ensure that the collision is inelastic, it is important to emphasize that our computer code is set to run the water discharge with slower velocity first, which will be collided by the faster one.

It is worth to note that this junction model in principle can be extended to include more than two merging branches, namely, by adding another discharge and momentum terms on the left hand side of (2) and (3), respectively. Furthermore, this model can also be modified to accommodate the river branch bifurcation cases.

An example of a more complicated junction model has been proposed previously in [21]. In that model, flow from different river channel does not experience inelastic collision. Instead, by defining control volume to each channel, the water from both channels is assumed to flow side by side in the subsequent channel, where the momentum change of each flow is determined by hydrostatic pressure and pressure that related to the change of its control volume as well as interfacial shear force between them. Another junction model is given in [22] which also considers the application of continuity and mass-momentum conservation law incorporated with momentum and energy correction parameters. The implementations of these models are likely not easy in large scale cases and local boundary conditions are needed. Comparing with these two models, it is clear that our junction model is far simpler in its implementation, but it is probably less accurate indeed.

In addition, we also assume that after collision the width $w_{3}$ and water level $h_{3}$ will change according to the following chosen relations:

$$
w_{3}=w_{1(2)} \exp \left(\alpha \frac{w_{1(2)}}{w_{2(1)}}\right)
$$

for $w_{1(2)}>w_{2(1)}$ and

$$
h_{3}=h_{1(2)} \exp \left(\beta \frac{h_{1(2)}}{h_{2(1)}}\right)
$$

for $h_{1(2)}>h_{2(1)}$. The symbols $\alpha$ and $\beta$ are small and dimensionless real parameters. These assumptions are taken to model the width and water level of river channel that resulted from the merging of two different branches. We consider the width and water level as two independent parameters since both are naturally predetermined. Here, these parameters are assumed to be uniform and they will 
be determined numerically. In general, however, one might consider that their values should not be the same for different junction and can be determined empirically. Indeed, one can choose another type of relation to model the width $w_{3}$ and water level $h_{3}$. However, based on our numerical experiment which will be presented in the next section, the relations given by (5) and (6) so far are the most applicable ones to meet the corresponding river parameters and certainly this assumption must be further clarified by field observation which is beyond the scope of this report.

To this end, it is well known that based on the following definition of Froude number for a channel with rectangular cross-section

$$
\operatorname{Fr}=\frac{v}{\sqrt{g \times h}}
$$

where $g$ is the actual gravitational acceleration, one can classify the flow regimes into subcritical $(\mathrm{Fr}<1)$, critical $(\mathrm{Fr}=1)$, and supercritical $(\mathrm{Fr}>1)$ flow [23]. It will be discussed on the next section that the model seems to accommodate only the case of subcritical flow.

\section{Results of Model Simulation and Discussion}

To simulate our model, we use the water discharge data sample found from our field surveys during dry season in August, 2013. Based on those data samples we consider dividing the 126 headwaters into five regions and choose Katulampa as the simulation point as shown in Figure 1(b). The corresponding data of headwaters and Katulampa point were considered as the associated initial and final conditions, respectively.

The initial flow velocity, width, and water level from field survey in each region are assumed to be uniform as given in Table 1. Prior to discussing the characteristics of our model with respect to the initial flow velocity and water level variations, we first simulate the flow velocity, water level, and width at Katulampa with initial values given in Table 1. Our simulation yields the following results: $v=0.94 \mathrm{~m} / \mathrm{s}$, $h=0.41 \mathrm{~m}$, and $w=70.01 \mathrm{~m}$. On the other hand, from field survey, we observed the following data: $v \approx 0.90 \mathrm{~m} / \mathrm{s}$, $h \approx 0.5 \mathrm{~m}$, and $w \approx 60.63 \mathrm{~m}$. To meet the simulation results that match Katulampa data, we adjusted by trial and error the parameters in (1), (5), and (6) and found the following values: $g_{\text {eff }}=9 \times 10^{-5} \mathrm{~m} / \mathrm{s}^{2}, \alpha=6.3 \times 10^{-3}$, and $\beta=5.5 \times 10^{-3}$, whereas in our computer code we run the initial water discharge from region 1 first and then from regions $2,3,4$, and 5 , respectively, since $v_{0,1}<v_{0,2}<v_{0,3}<v_{0,4}<v_{0,5}$. It is worth to note that by assuming $g \sim 9.81 \mathrm{~m} / \mathrm{s}^{2}$ all these velocities at headwaters and Katulampa are related to subcritical flows according to Froude number given by (7).

The simulation results of flow velocity, water level, and width of the whole catchment area of CR are given in Figure 3. Comparing to our data sample, the simulated flow velocity width and water level do not represent most of the actual conditions although at Katulampa these quantities are in good agreement. This can be explained as a consequence of not applying actual data of the whole headwaters to our
TABLE 1: Initial flow velocity $\left(v_{0}\right)$, width $\left(w_{0}\right)$, and water level $\left(h_{0}\right)$ of each chosen region.

\begin{tabular}{lccc}
\hline Region & $v_{0}(\mathrm{~m} / \mathrm{s})$ & $w_{0}(\mathrm{~m})$ & $h_{0}(\mathrm{~m})$ \\
\hline 1 & 0.342 & 4.85 & 0.20 \\
2 & 0.429 & 3.12 & 0.10 \\
3 & 0.437 & 1.81 & 0.30 \\
4 & 0.527 & 1.55 & 0.30 \\
5 & 0.940 & 2.77 & 0.40 \\
\hline
\end{tabular}

model. One might expect that the use of actual data of all headwaters and considering position-dependent $g_{\text {eff }}, \alpha$, and $\beta$ will give fairly accurate results with tolerable deviations. As shown in Figure 3(a), it is found that at every river branch junction, the flow velocity of merged water discharge is getting slower due to inelastic collision given by (3), which corresponds to kinetic energy losses phenomenon.

Next, to simulate the characteristics of flow velocity at Katulampa, we vary the initial flow velocity at headwater of particular region while keeping the velocity of other regions the same. Given in Table 2 are five different variations of the first one, denoted by letters $\mathrm{A}, \mathrm{B}, \mathrm{C}, \mathrm{D}$, and $\mathrm{E}$, with the corresponding results depicted in Figure 4. In variation A, we vary the initial flow velocity $v_{0,1}=0-0.4290 \mathrm{~m} / \mathrm{s}$. It is found that the flow velocity at Katulampa exhibits nonlinear variation as shown in Figure 4(a). However, it should be noted that the change is relatively small. In contrast, as shown in Figure 4(b), we observe for variation B, where $v_{0,2}=0.3420-0.4290 \mathrm{~m} / \mathrm{s}$ variation is considered, that the flow velocity at Katulampa does not vary at all. On the other hand, the other different characteristics are found for variations $\mathrm{C}$ and $\mathrm{D}$, with the corresponding variations given as follows: $v_{0,3}=0.4290-0.5270 \mathrm{~m} / \mathrm{s}$ and $v_{0,4}=$ $0.4370-0.9400 \mathrm{~m} / \mathrm{s}$, respectively. As shown in Figures 4(c) and $4(\mathrm{~d})$, both variations exhibit opposite characteristics, where in variation $\mathrm{C}$ the flow velocity is increasing almost linearly, while for variation $\mathrm{D}$ the flow velocity is decreasing linearly. In the meantime, the variation E given in Figure 4(e) is similar to variation $A$ where its variation is nonlinear with respect to the linear variation of initial flow velocity $v_{0,5}=$ $0.5270-14 \mathrm{~m} / \mathrm{s}$.

For comparison, we also consider another five variations of the second one, denoted by letters F, G, H, I, and J, with the corresponding variations of initial flow velocity of each region given in Table 3. Here, we exchange the initial flow velocity between region 4 and region 5 such that $v_{0,4}>v_{0,5}$. The results are depicted in Figure 5. Comparing variations $\mathrm{A}, \mathrm{B}$, and $\mathrm{C}$ and variations $\mathrm{F}, \mathrm{G}$, and $\mathrm{H}$ of Figures 4(a)4(c) and Figures 5(a)-5(c), respectively, we see that similar characteristics are exhibited for variations of regions 1,2 , and 3 , respectively, but with different flow velocity magnitudes. Interestingly, this similarity is not the case for variations I and J given in Figures 5(d) and 5(e), respectively, where both variations demonstrate flat characteristics. These results are in contrast to the previous variations $\mathrm{D}$ and $\mathrm{E}$ given in Figures 4(d) and 4(e). 


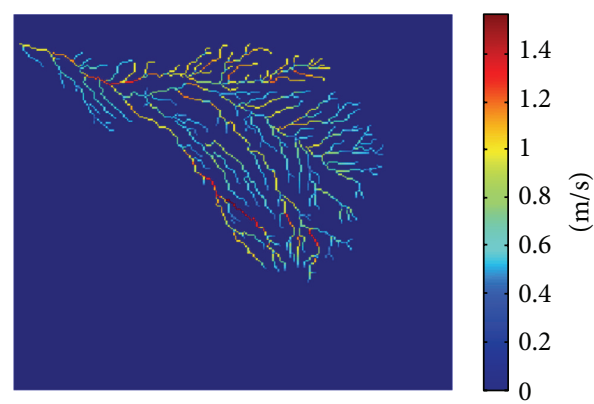

(a)

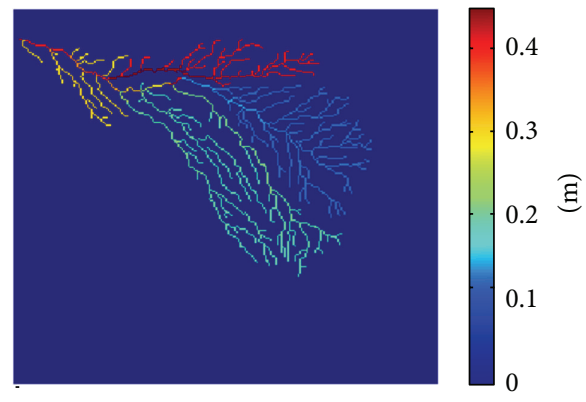

(b)

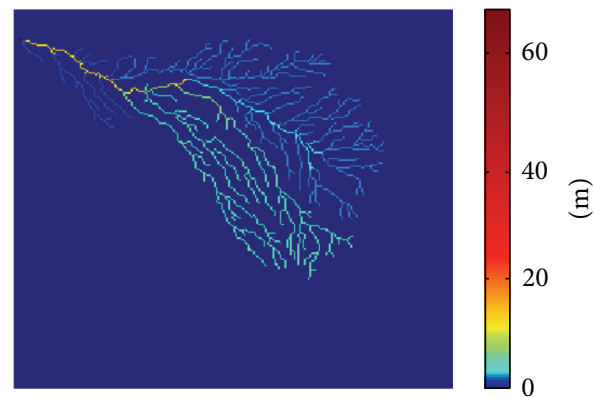

(c)

FIGURE 3: Global pattern of (a) flow velocity, (b) water level, and (c) width. In these figures we set to zero all the corresponding values outside the river channels.

TABLE 2: First variation of initial flow velocity.

\begin{tabular}{lccccc}
\hline Variation & $v_{0,1}(\mathrm{~m} / \mathrm{s})$ & $v_{0,2}(\mathrm{~m} / \mathrm{s})$ & $v_{0,3}(\mathrm{~m} / \mathrm{s})$ & $v_{0,4}(\mathrm{~m} / \mathrm{s})$ & 0.5270 \\
\hline A & $0-0.4290$ & 0.4290 & 0.4370 & 0.5270 & 0.9400 \\
B & 0.3420 & $0.3420-0.4370$ & 0.4370 & 0.5270 & 0.9400 \\
C & 0.3420 & 0.4290 & $0.4290-0.5270$ & $0.4370-0.9400$ & 0.9400 \\
D & 0.3420 & 0.4290 & 0.4370 & 0.9270 & 0.9400 \\
E & 0.3420 & 0.4290 & 0.4370 & & $0.5270-14$ \\
\hline
\end{tabular}

To complete our investigation on the flow velocity characteristics at Katulampa with respect to initial flow velocity variation, we also simulate the model by uniformly increasing the value of initial flow velocity of each region. The results are given in Figure 6 showing nonlinear variation of velocity at Katulampa with respect to the uniform increment of all initial flow velocities by $\Delta v_{0}$.

Clearly, since it is considered that the water level does not vary and that the related velocity at Katulampa tends to grow exponentially, then the corresponding Froude number at that point, which is given by (7), can probably be of Fr $\gg 1$. Therefore, based on this fact it is safe to say that our model most likely cannot describe the supercritical flow in a fairly accurate way.

All these results obviously indicate that the influence of initial flow velocity variation at headwaters will lead to specific characteristics of flow velocity at lower land. However, the associated characteristics cannot be easily explained due to complex interaction under inelastic collision among the corresponding river branches. This situation can be exemplified by the nonlinear characteristic of variation $\mathrm{E}$ which is clearly different compared to variation I with flat characteristic, although both variations have the same initial flow velocity variation on the related region $(0.5270-14 \mathrm{~m} / \mathrm{s}$ ) and the location of the corresponding headwaters is relatively close to Katulampa as shown in Figure 1.

We have discussed previously in Section 3 that in general the parameter $g_{\text {eff }}$ depends on water level. Therefore, in addition to the aforementioned variations, we have also investigated the characteristics of flow velocity and water level at Katulampa by increasing linearly the water level of each headwater as follows:

$$
h(\Delta h)=h_{0}\left[1+\frac{\Delta h}{h_{0}}\right]
$$

with $\Delta h=0.1 \times n \mathrm{~m}$, where $n$ is an integer. In the meantime, the effective gravitational acceleration is considered to increase linearly based on the following equation:

$$
g_{\mathrm{eff}}(\Delta h)=g_{\mathrm{eff}}(0)\left[1+\frac{\Delta h}{h_{0}}\right]
$$




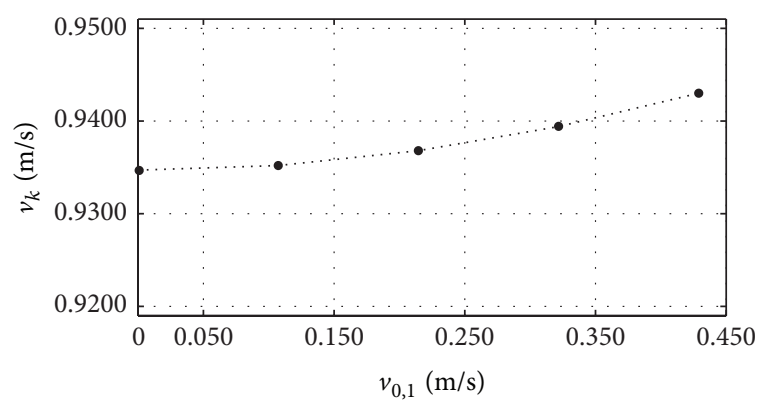

(a)

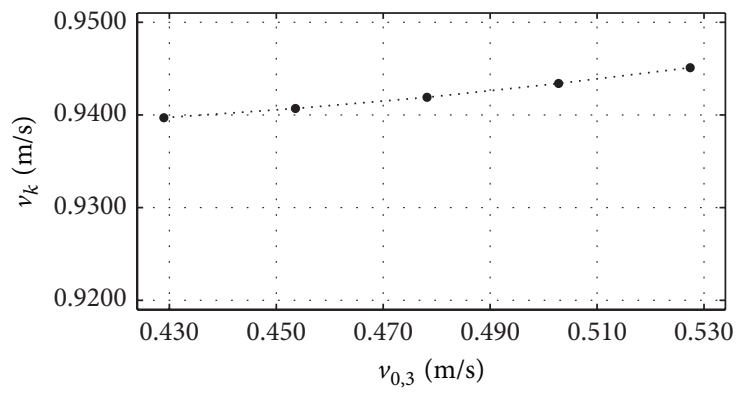

(c)

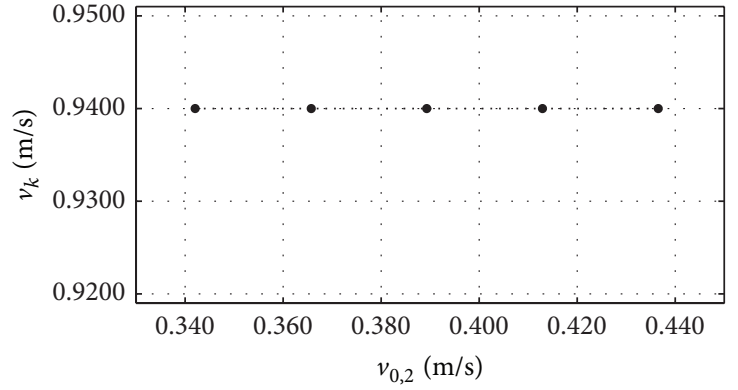

(b)

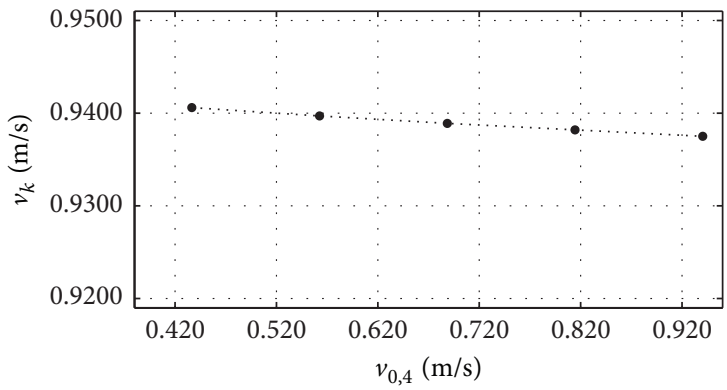

(d)

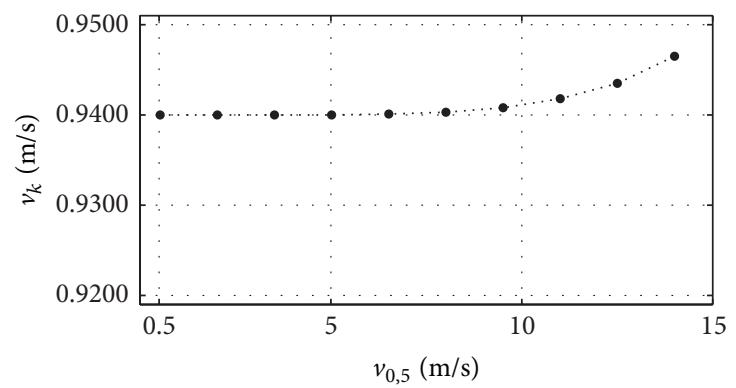

(e)

Figure 4: Characteristics of flow velocity at Katulampa with respect to the first variation of initial flow speed (a) A, (b) B, (c) C, (d) D, and (e) E.

TABLE 3: Second variation of initial flow velocity.

\begin{tabular}{lccccc}
\hline Variation & $v_{0,1}(\mathrm{~m} / \mathrm{s})$ & $v_{0,2}(\mathrm{~m} / \mathrm{s})$ & $v_{0,3}(\mathrm{~m} / \mathrm{s})$ & $v_{0,4}(\mathrm{~m} / \mathrm{s})$ & 0.9400 \\
F & $0-0.4290$ & 0.4290 & 0.4370 & 0.9400 & 0.5270 \\
$\mathrm{G}$ & 0.3420 & $0.3420-0.4370$ & 0.4370 & 0.9400 & 0.5270 \\
$\mathrm{H}$ & 0.3420 & 0.4290 & $0.4290-0.5270$ & $0.5270-14$ & 0.5270 \\
$\mathrm{I}$ & 0.3420 & 0.4290 & 0.4370 & 0.9400 & 0.5270 \\
$\mathrm{~J}$ & 0.3420 & 0.4290 & 0.4370 & & $0.4370-0.9400$ \\
\hline
\end{tabular}

which is taken under the assumption that higher water level will flow more easily. Here $h_{0}$ is given in Table 1 . The result is shown in Figure 7. It is found that the flow velocity variation at Katulampa increases nonlinearly with tendency of saturation while the corresponding water level increases linearly.

Finally, it should be admitted that our simple model must be further examined by field observation which should be conducted in relatively long time period. However, this model can be used to determine and predict qualitatively the characteristics of river flow velocity in large scale. In addition, for a relatively small grid DEM, in principle, the calculated velocity, water level, and width can be used as initial condition of time-dependent SVEs.

\section{Summary}

We have discussed our simple computer based model for simulating the river flow velocity. We consider Ciliwung River as the area of simulation where the corresponding digital elevation model (DEM) is based on SRTM data from USGS with $90 \times 90 \mathrm{~m}^{2}$ resolution and modified by $15 \times 15 \mathrm{~m}^{2}$ as well as data from field survey. 


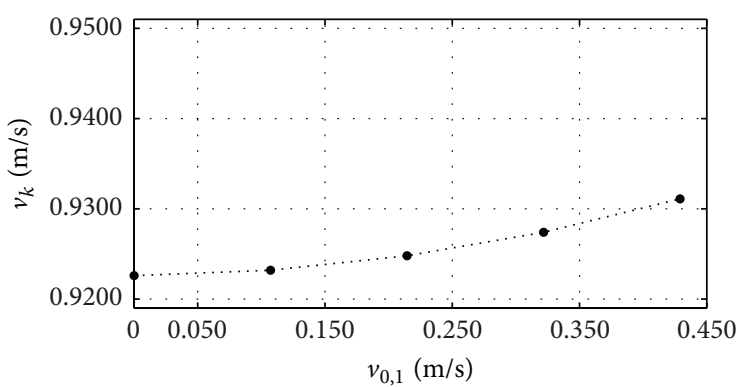

(a)

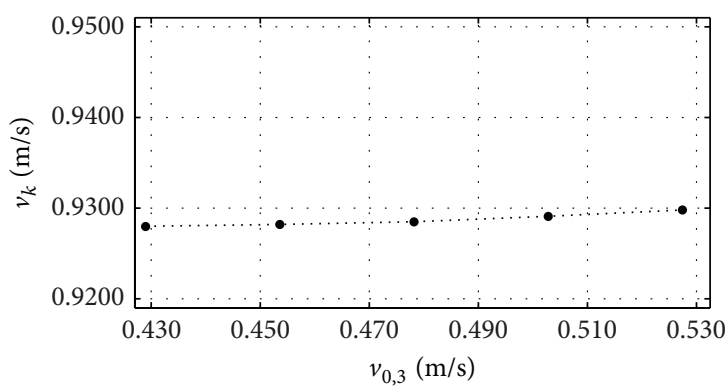

(c)

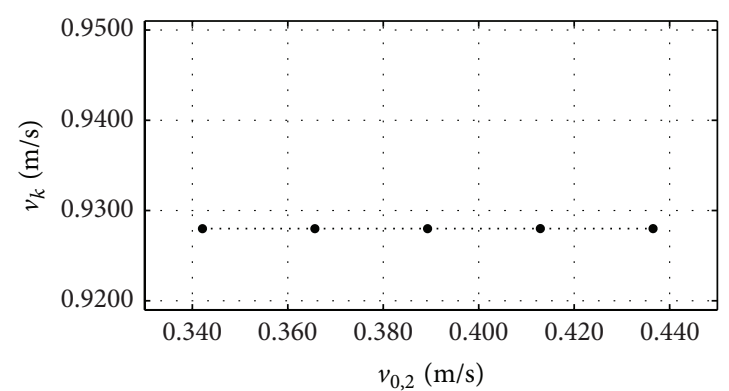

(b)

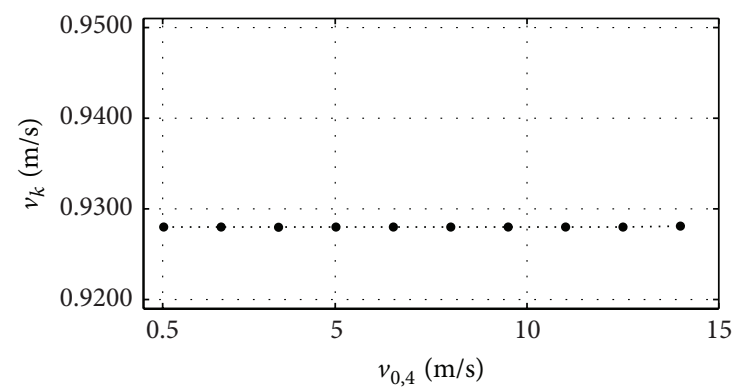

(d)

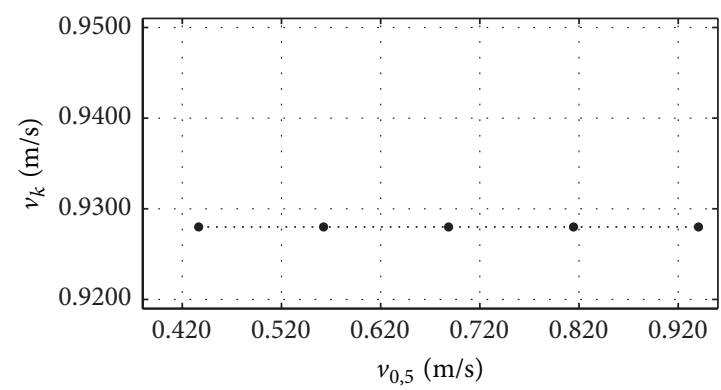

(e)

FIGURE 5: Characteristics of flow velocity at Katulampa with respect to the second variation of initial flow speed (a) F, (b) G, (c) H, (d) I, and (e) J.

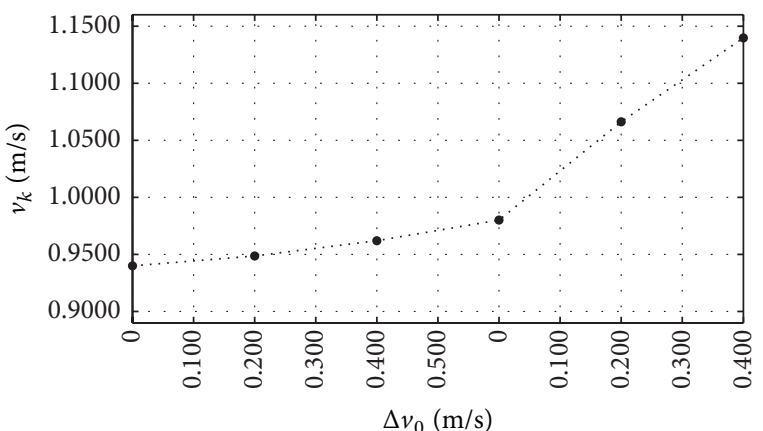

FIgURE 6: Characteristic of flow velocity at Katulampa with respect to uniform increasing of initial flow speed of all regions.

The flow velocity is described by equation of motion of falling body in inclined plane due to gravitational force.
We define the effective gravitational acceleration parameter to accommodate the real condition of river channel. At the junction of two river branches we assume that the merged flow velocity is determined by inelastic collision. It is found that our model can determine the flow velocity at Katulampa in good agreement with observation data. The variations of initial flow velocity of certain region in the Ciliwung River headwaters show various characteristics that we suspect to occur due to complex interaction among the river branches. This simple model can be used to determine and predict the characteristics of river flow velocity at subcritical level as well as providing an initial condition for time-dependent Saint Venant equations.

\section{Conflict of Interests}

The authors declare that there is no conflict of interests regarding the publication of this paper. 


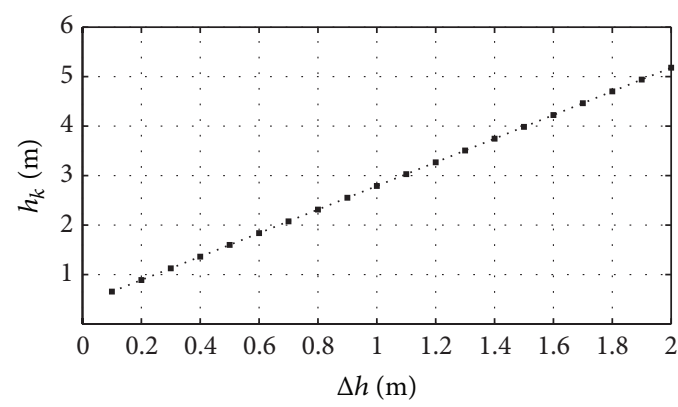

(a)

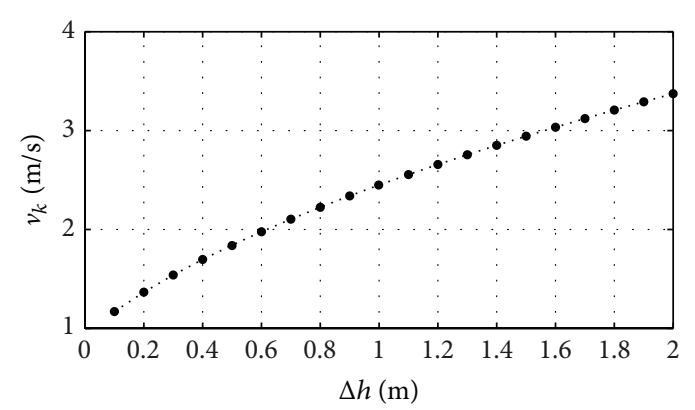

(b)

Figure 7: (a) Characteristics of water level and (b) flow velocity (dashed circle) at Katulampa with respect to uniform increasing of initial water level of all regions.

\section{Acknowledgment}

This work was funded by BOPTN Research Grant of year 2013 from Directorate of Higher Education, Ministry of National Education and Culture, Republic of Indonesia, under Contract no. 198/IT3.41.2/L2/SPK/2013.

\section{References}

[1] W. Wu, Computational River Dynamics, Taylor \& Francis, London, UK, 2002.

[2] A. Giacometti, A. Maritan, and J. R. Banavar, "Continuum model for river networks," Physical Review Letters, vol. 75, no. 3, pp. 577-580, 1995.

[3] F. Métivier, "Diffusivelike buffering and saturation of large rivers," Physical Review E: Statistical Physics, Plasmas, Fluids, and Related Interdisciplinary Topics, vol. 60 , no. 5, pp. 58275832, 1999.

[4] A. Giacometti, "Local minimal energy landscapes in river networks," Physical Review E, vol. 62, no. 5, pp. 6042-6051, 2000.

[5] G. Yan, J. Zhang, H. Wang, and L. Guo, "Simple stochastic lattice gas automaton model for formation of river networks," Physical Review E, vol. 78, no. 6, Article ID 066102, 2008.

[6] G. Caldarelli, A. Giacometti, A. Maritan, I. Rodriguez-Iturbe, and A. Rinaldo, "Randomly pinned landscape evolution," Physical Review E-Statistical Physics, Plasmas, Fluids, and Related Interdisciplinary Topics, vol. 55, no. 5, pp. R4865-R4868, 1997.

[7] X. Lai, J. Jiang, Q. Liang, and Q. Huang, "Large-scale hydrodynamic modeling of the middle Yangtze River Basin with complex river-lake interactions," Journal of Hydrology, vol. 492, pp. 228-243, 2013.

[8] M. E. Akiner and A. Akkoyunlu, "Modeling and forecasting river flow rate from the Melen watershed, Turkey," Journal of Hydrology, vol. 456-457, pp. 121-129, 2012.

[9] K. Verzano, I. Bärlund, M. Flörke et al., "Modeling variable river flow velocity on continental scale: current situation and climate change impacts in Europe," Journal of Hydrology, vol. 424-425, pp. 238-251, 2012.

[10] G. Steinebach, S. Rademacher, P. Rentrop, and M. Schulz, "Mechanisms of coupling in river flow simulation systems," Journal of Computational and Applied Mathematics, vol. 168, no. 1-2, pp. 459-470, 2004.

[11] C. H. David, Z.-L. Yang, and S. Hong, "Regional-scale river flow modeling using off-the-shelf runoff products, thousands of mapped rivers and hundreds of stream flow gauges," Environmental Modelling and Software, vol. 42, pp. 116-132, 2013.

[12] F. Liu and B. R. Hodges, "Applying microprocessor analysis methods to river network modelling," Environmental Modelling \& Software, vol. 52, pp. 234-252, 2014.

[13] R. Moussa and C. Bocquillon, "Approximation zones of the Saint-Venant equations for flood routing with overbank flow," Hydrology and Earth System Sciences, vol. 4, no. 2, pp. 251-261, 2000.

[14] R. Szymkiewicz, "Solution of the inverse problem for the Saint Venant equations," Journal of Hydrology, vol. 147, no. 1-4, pp. 105-120, 1993.

[15] E. Bladé, M. Gómez-Valentín, J. Dolz, J. L. Aragón-Hernández, G. Corestein, and M. Sánchez-Juny, "Integration of 1D and 2D finite volume schemes for computations of water flow in natural channels," Advances in Water Resources, vol. 42, pp. 17-29, 2012.

[16] S. K. Ooi, M. P. M. Krutzen, and E. Weyer, "On physical and data driven modelling of irrigation channels," Control Engineering Practice, vol. 13, no. 4, pp. 461-471, 2005.

[17] V. dos Santos Martins, M. Rodrigues, and M. Diagne, "A multimodel approach to Saint-Venant equations: a stability study by LMIs," International Journal of Applied Mathematics and Computer Science, vol. 22, no. 3, pp. 539-550, 2012.

[18] T. G. Lich and L. K. Luat, "Boundary conditions for the twodimensional Saint-Venant equation system," Applied Mathematical Modelling, vol. 16, no. 9, pp. 498-502, 1992.

[19] R. Ghostine, R. Mose, J. Vazquez, A. Ghenaim, and C. Grégoire, "Two-dimensional simulation of subcritical flow at a combining junction: luxury or necessity?" Journal of Hydraulic Engineering, vol. 136, no. 10, Article ID 004010QHY, pp. 799-805, 2010.

[20] http://gdex.cr.usgs.gov/gdex/.

[21] S. Shabayek, P. Steffler, and F. Hicks, "Dynamic model for subcritical combining flows in channel junctions," Journal of Hydraulic Engineering, vol. 128, no. 9, pp. 821-828, 2002.

[22] C. C. Hsu, W. J. Lee, and C. H. Chang, "Subcritical open-channel junction flow," Journal of Hydraulic Engineering, vol. 124, no. 8, pp. 847-855, 1998.

[23] H. Chanson, Hydraulics of Open Channel Flow, ButterworthHeinemann, Oxford, UK, 2004. 

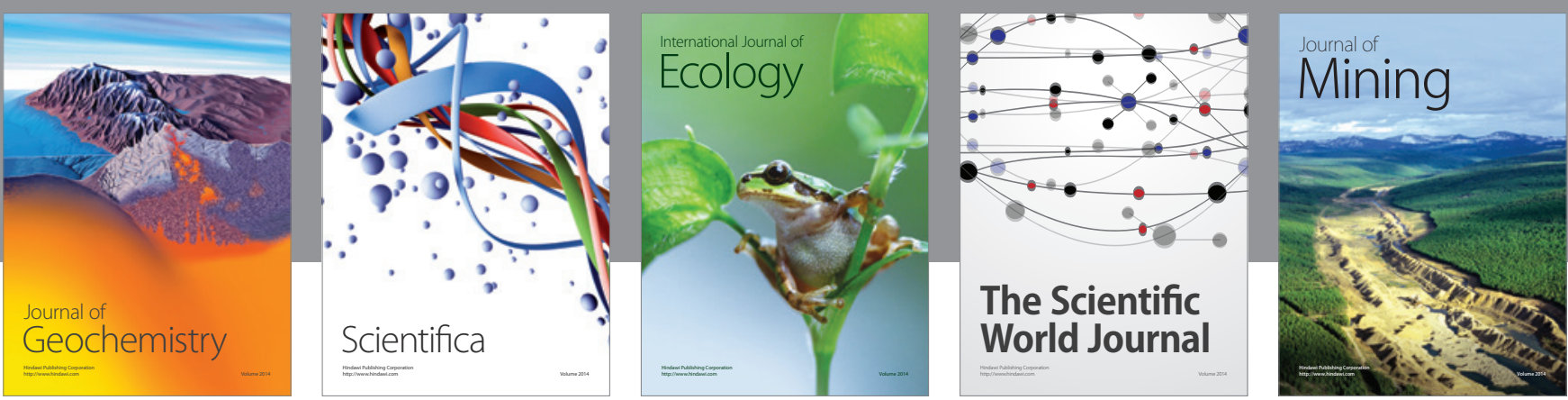

The Scientific World Journal
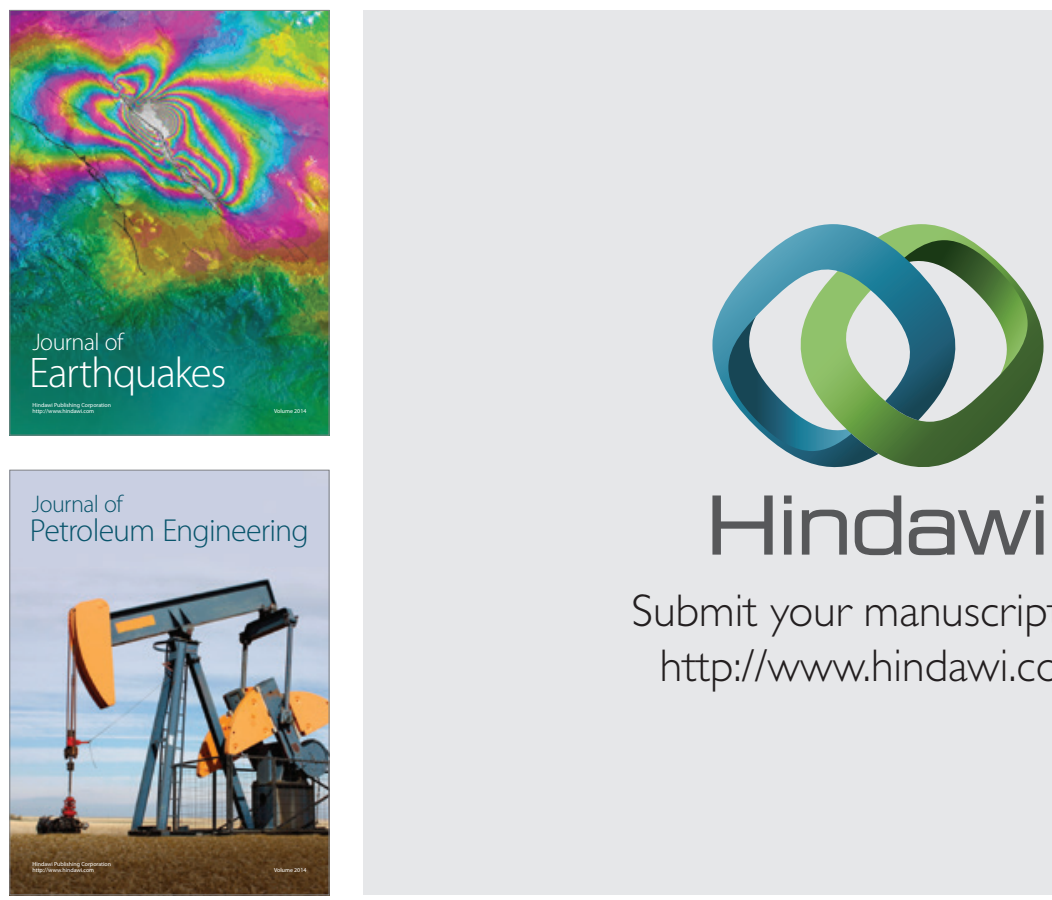

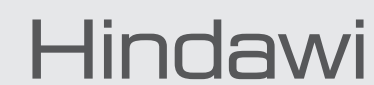

Submit your manuscripts at

http://www.hindawi.com
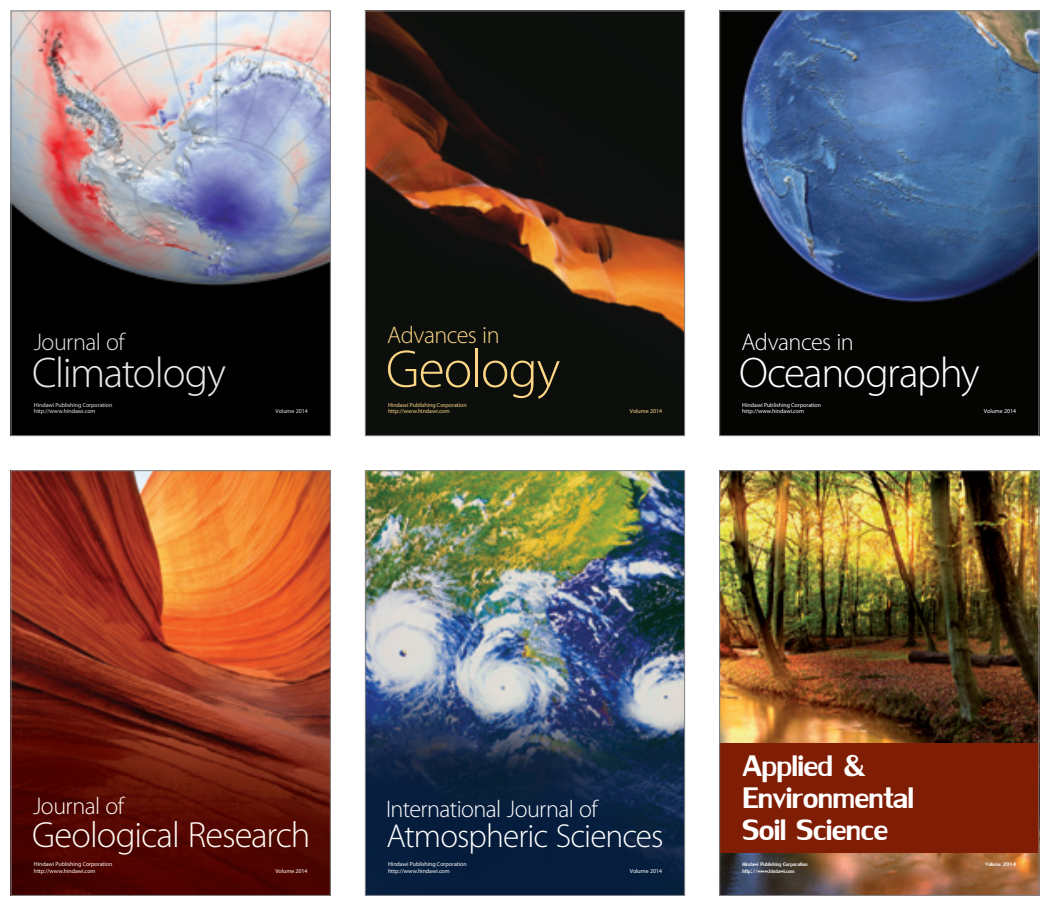
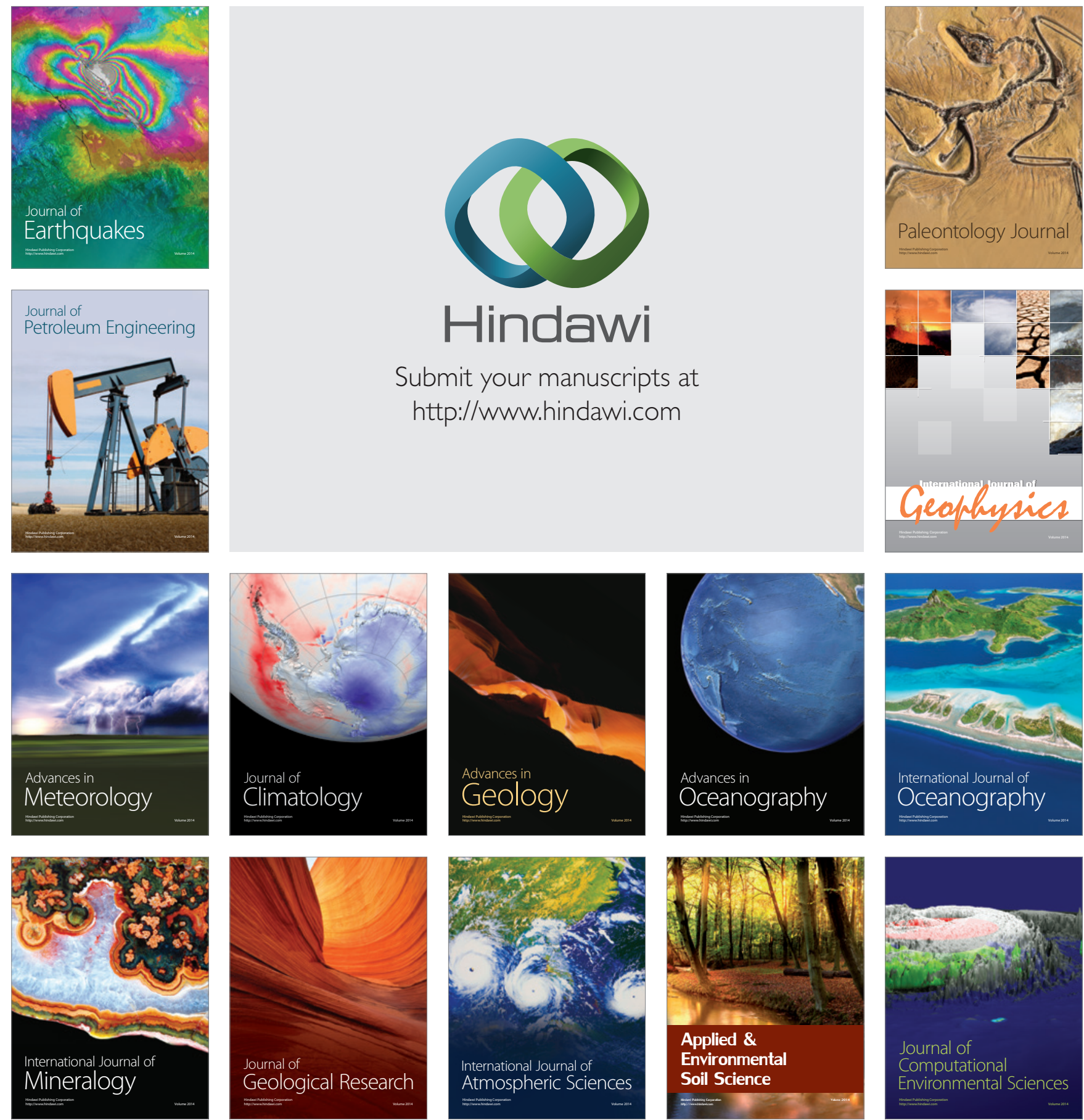